\title{
Resistance to Antimicrobials and Biofilm Formation in Staphylococcus aureus Isolated from Bovine Mastitis in Beni-Suef Governorate
}

\author{
Hala S. H. Salam \\ Department of Bacteriology, Mycology and Immunology, \\ Faculty of Veterinary Medicine, Beni-Suef University, Beni- \\ Suef, Egypt.
}

\begin{abstract}
TAPHyLOCOCCUS (S.) aureus is one of the most prevalent causes $\checkmark$ most prevalent causes of clinical and subclinical bovine mastitis. A bovine mastitis. A total of 400 lactating cows housed in 5 farms in BeniSuef governorate, Egypt, were examined for presence of either clinical or subclinical mastitis. The examination revealed that $20(5 \%)$ and 78 (21.8\%) of animals showed clinical and subclinical mastitis criteria, respectively. Twenty three $S$. aureus isolates were recovered from 98 milk samples in a prevalence of $23.5 \%$. Antimicrobial susceptibility testing of them against 8 compounds revealed that only one isolate was susceptible to all the tested antibiotics while high percentage $(n=14$, $60.9 \%$ ) were resistant to more than one antibiotic. The highest percentage of resistance $(82.6 \%)$ was documented against penicillin. Multiple drug resistance was observed in $26.1 \%$ of the tested isolates. Additionally 11(47.8\%) isolates were resistant to cefoxitin so they were categorized phenotypically as methicillin-resistant S.aureus. All the recovered isolates were seeded on congo red agar to evaluate their biofilm forming ability and $18(78.3 \%)$ of them were recorded as biofilm producers. Investigation of $i c a A$, icaD and bap genes among the recovered isolates revealed that icaA and icaD were coexisted in 21 isolates $(91.3 \%)$ while bap gene was existed in only one isolate $(4.3 \%)$.
\end{abstract}

Keywords: Mastitis, Staph. aureus, Biofilm, Resistance.

Bovine mastitis is defined as an inflammation of the mammary gland which is still the most predominant and costly disease in the dairy industry (ThompsonCrispi et al., 2014). Staphylococcus (S.) aureus is one of the major causes of either clinical or subclinical bovine mastitis (Bergonier et al., 2014). S. aureus mastitis is usually chronic in nature that makes it difficult to cure with high recurrent infection rate (Cucarella et al., 2004 and Melchior, 2006).

Antimicrobial treatment is critical in the control of $S$. aureus mastitis however; resistance against multiple antimicrobials especially to beta-lactams favors treatment failures and its persistence in the herd (Kumar et al., 2010).

An additional common reason for the persistence of $S$. aureus in the udder is the biofilm formation, biofilms are bacterial communities aggregate in an exopolysaccharide slime matrix of their own synthesis that adhered to surfaces (Costerton et al., 1999 and Vancraeynest et al., 2004). 
Bacteria in biofilm are less invasive but resistant to the host's defense mechanisms and to most of therapeutic interference, however at any time biofilm is capable to shed planktonic cells (free floating) that grow rapidly and occupy other surfaces (Melchior, 2006).

Biofilm formation involves two consecutive steps: adhesion of cells to a surface shadowed by cell-cell adhesion, creating several layers of cells (Cramton et al., 1999). Intercellular adhesion requires the polysaccharide intercellular adhesin (PIA) or polymeric N-acetyl-glucosamine (PNAG) which encoded by the ica operon (icaABCD) (Götz, 2002), among them icaA and icaD genes have been reported to play a major role in the biofilm formation in $S$. aureus isolated from bovine mastitis (Vasudevan et al., 2003).

Additionally some proteins named as biofilm associated proteins (Bap) which encoded by bap gene are known to contribute in the formation of $S$. aureus communities (Latasa et al., 2006).

Since antimicrobial susceptibility and biofilm forming ability of S. aureus are of crucial concern all over the world, the purpose of this study was to determine the antimicrobial susceptibility behavior, biofilm forming ability on congo red agar, presence of icaA, icaD and bap genes in a collection of $S$. aureus isolates of intramammary origin in Beni-Suef Governorate, Egypt.

\section{Material and Methods}

A total of 400 lactating cows housed in 5 different farms were examined for presence of udder inflammation signs or alterations in milk (clinical mastitis). The subclinical mastitis was detected in animals that showed absence of signs or alterations on milk but revealed positive results on California Mastitis Test (CMT) (Schalm and Noorlander, 1957).

An average of $5 \mathrm{~mL}$ of milk was collected under aseptic conditions from each animal (showed either clinical or subclinical mastitis).

$10 \mu \mathrm{l}$ of milk were plated on Baird Parker agar, incubated at $37^{\circ} \mathrm{C}$ for $48 \mathrm{~h}$. Black colonies with a clear halo zone were considered presumptive of $S$. aureus. These presumptive colonies were examined by Gram's staining and catalase test.

Complete biochemical identification of $S$. aureus was carried out in accordance to Collee et al. (1996).

\section{Antimicrobial susceptibility testing}

All the isolates were tested for their antimicrobial susceptibility using the disk-diffusion method on Mueller-Hinton agar (Oxoid, UK) according to the Clinical and Laboratory Standards Institute (CLSI, 2013). Disks impregnated with the following antibiotics were used: penicillin G (P $10 \mathrm{U})$, gentamicin $(\mathrm{CN} 10 \mu \mathrm{g})$,

Egypt. J. Vet. Sci. Vol. 45-46 (2014 - 2015) 
cefoxitin (FOX $30 \mu \mathrm{g}$ ), ciprofloxacin (CIP $5 \mu \mathrm{g}$ ), doxycycline (DO $30 \mu \mathrm{g}$ ), rifampicin (RD $5 \mu \mathrm{g}$ ), spectinomycin (SH $100 \mu \mathrm{g}$ ) and vancomycin (VA $30 \mu \mathrm{g}$ ).

Resistance against cefoxitin disk indicated methicillin resistant $S$. aureus (MRSA) phenotype according to the CLSI (2013).

Phenotypic detection of biofilm production on congo red agar

Biofilm production in $S$. aureus strains was performed by cultivation on congo red agar (CRA) as previously described (Freeman et al., 1989). Strains producing black colonies with a rough, dry and crystalline consistency were considered biofilm producers. Strains producing red colonies with rough, dry and crystalline consistency or smooth colonies were classified as biofilm nonproducers.

DNA extraction and PCR reaction for detection of icaA, icaD and bap genes.

S.aureus isolates were inoculated on Triptycase Soy Agar. After incubation period, fresh colonies were suspended in $500 \mu \mathrm{l}$ sterile saline. DNA was extracted from the suspension using a QIAamp DNA Mini Kit according to the manufacturer's instructions (Qiagen).

PCR reaction was carried out to detect icaA and icaD genes as previously described by Ciftci et al. (2009) while for detection of bap gene the conditions was previously described by Cucarella et al. (2001).

The sequences of primers are listed in Table 1. The amplified products were visualized by electrophoresis on $1.5 \%$ agarose gel.

TABLE 1. List of primers used for detection of icaA, icaD and bap genes.

\begin{tabular}{|c|c|c|c|}
\hline Primer & Sequence (5'-3') & Product (bp) & Reference \\
\hline \multirow[t]{2}{*}{$i c a A$} & $\begin{array}{l}\text { F-CCT AAC TAA } \\
\text { CGAAAG GTA G }\end{array}$ & \multirow[t]{2}{*}{1315} & \multirow{4}{*}{$\begin{array}{l}\text { Ciftci } \\
\text { et al., } 2009\end{array}$} \\
\hline & $\begin{array}{l}\text { R-AAG ATA TAG } \\
\text { CGATAA GTG C }\end{array}$ & & \\
\hline \multirow[t]{2}{*}{$i c a D$} & $\begin{array}{l}\text { F-AAA CGT AAG } \\
\text { AGAGGT GG }\end{array}$ & \multirow[t]{2}{*}{381} & \\
\hline & $\begin{array}{l}\text { R-GGC AAT ATG } \\
\text { ATCAAG ATA }\end{array}$ & & \\
\hline \multirow[t]{2}{*}{ Bap } & $\begin{array}{l}\text { F-CCCTATATCGAA } \\
\text { GGTGTAGAATTG }\end{array}$ & \multirow[t]{2}{*}{971} & \multirow[t]{2}{*}{$\begin{array}{l}\text { Cucarella } \text { et al., } \\
2001\end{array}$} \\
\hline & $\begin{array}{l}\text { R-GCTGTTGAAGTTA } \\
\text { ATACTGTACCTGC }\end{array}$ & & \\
\hline
\end{tabular}




\section{Results}

Out of 400 lactating cows, 20 (5\%) and 78 (21.8\%) animals showed clinical and subclinical mastitis criteria respectively.

Twenty three $S$. aureus isolates were recovered from 98 milk samples in a prevalence of $23.5 \%$, of them 5 and 18 isolates were recovered from clinical and subclinical cases in prevalence of 25 and $23.1 \%$ respectively.

\section{Antimicrobial susceptibility}

Antimicrobial susceptibility testing of 23 S.aureus isolates against 8 compounds revealed that only one isolate was susceptible to all the tested antibiotics while high percentage of them $(n=14,60.9 \%)$ were resistant to more than one antibiotic. The remaining isolates revealed resistance in a variable prevalence. The highest percentage of resistance $(82.6 \%)$ was documented against penicillin followed by cefoxitin and spectinomycin in a prevalence of 47.8 and $21.7 \%$ respectively (Table 2 ).

All the tested isolates were susceptible to vancomycin. Multiple drug resistance (MDR) was observed in $26.1 \%$ of the tested isolates. Additionally $11(47.8 \%)$ isolates were resistant to cefoxitin so they were categorized phenotypically as methicillin-resistant S.aureus (MRSA).

TABLE 2. Antimicrobial susceptibility pattern of $S$. aureus isolates recovered from milk samples.

\begin{tabular}{|l|c|c|c|c|c|c|}
\hline \multirow{2}{*}{ Antimicrobial agent } & \multicolumn{2}{|c|}{ Sensitive } & \multicolumn{2}{c|}{ Intermediate } & \multicolumn{2}{c|}{ Resistant } \\
\cline { 2 - 7 } & No & $\mathbf{\%}$ & No & \% & No & \% \\
\hline Penicillin & 4 & 17.4 & 0 & 0 & 19 & 82.6 \\
\hline Spectinomycin & 4 & 17.4 & 14 & 60.9 & 5 & 21.7 \\
\hline Cefoxitin & 12 & 52.2 & 0 & 0 & 11 & 47.8 \\
\hline Rifampicin & 14 & 60.9 & 6 & 26.1 & 3 & 13 \\
\hline Gentamicin & 16 & 69.6 & 5 & 21.7 & 2 & 8.7 \\
\hline Doxycycline & 17 & 74 & 3 & 13 & 3 & 13 \\
\hline Ciprofloxacin & 17 & 74 & 5 & 21.7 & 1 & 4.3 \\
\hline Vancomycin & 23 & 100 & 0 & 0 & 0 & 0 \\
\hline
\end{tabular}

No: number of isolates.

$\%$ : percentage in relation to the total isolates.

Determination of biofilm production on congo red agar (Fig. 1)

All the recovered isolates were seeded on CRA to evaluate their biofilm forming ability and $18(78.3 \%)$ of them were recorded as biofilm producers.

Biofilm Related Genes (Fig. 2)

Investigation of $i c a A$, icaD and bap genes among the recovered isolates revealed that $i c a A$ and $i c a D$ were coexisted in 21 isolates $(91.3 \%)$ while bap gene was existed in only one isolate $(4.3 \%)$.

Egypt. J. Vet. Sci. Vol. 45-46 (2014 - 2015) 


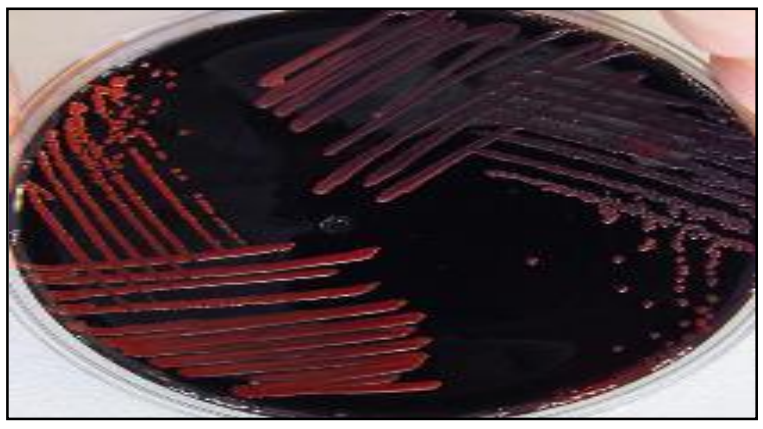

Fig. 1. Showed biofilm producer (black colonies) and non-biofilm producer (red colonies) on congo red agar.

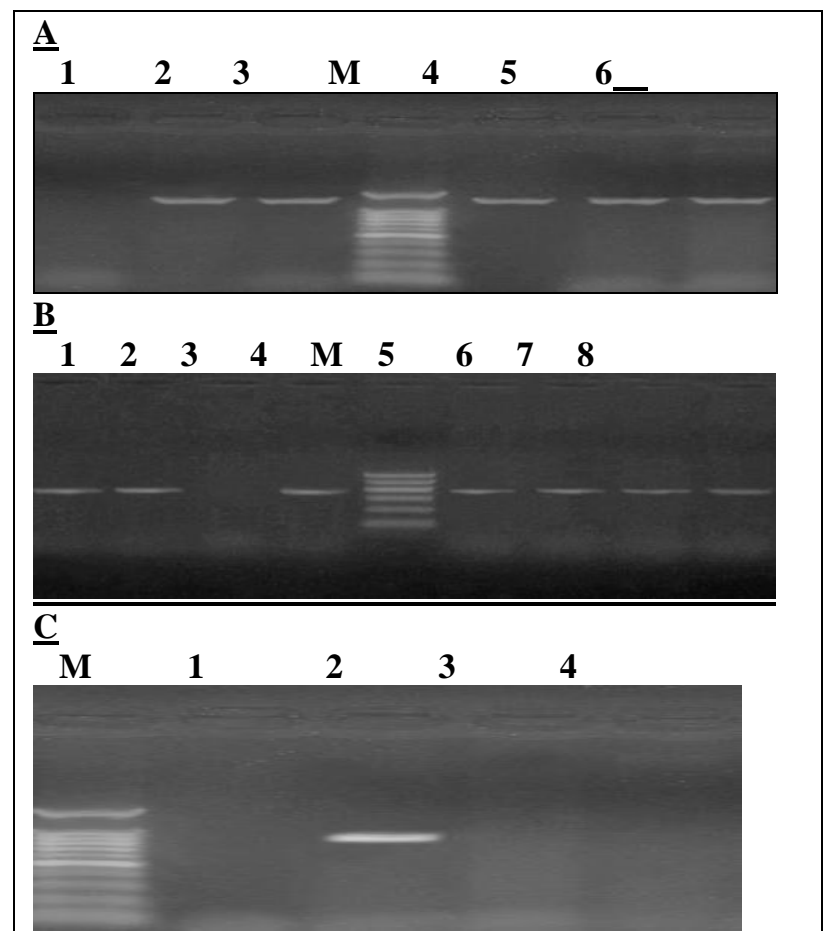

Fig. 2. Agarose gel electrophoresis of PCR products stained with ethidium bromide. (A) icaA gene (1315bp), M: 100 bp plus ladder (Size range: 100-1500 bp) positive samples: lane 2, 3, 4, 5, 6: negative samples: lane 1

(B) icaD gene (381 bp), M: 100 bp ladder (Size range: 100-1500 bp): positive samples: 1, 2,4,5,6,7,8: negative samples: lane 2

(C) bap gene ( $971 \mathrm{bp}), \mathrm{M}$ : $100 \mathrm{bp}$ plus ladder (Size range: 100-1500 bp) positive samples: lane 2 negative samples: lane 1,3,4.

Egypt. J. Vet. Sci. Vol. 45-46 (2014 - 2015) 


\section{Discussion}

The present study was carried on 400 lactating cows reared in five farms located in Beni-Suef governorate which is situated in the center of Egypt. Out of them, $20(5 \%)$ and $78(21.8 \%)$ animals showed clinical and subclinical mastitis criteria respectively.

Twenty three $S$. aureus isolates were recovered from the cases of mastitis in a prevalence of $23.5 \%$. This high proportion concurs with that of previous studies in Egypt and worldwide (Gianneechini et al., 2002 and Amin et al., 2011).

All the recovered isolates were tested for their antimicrobial susceptibility against 8 antimicrobial agents using disk diffusion method and a high percentage of these isolates $(60.9 \%)$ showed resistance against more than one antibiotic besides MDR among $26.1 \%$ of them. Several reports all over the world have described MDR against S. aureus (Kumar et al., 2010 and Shi et al., 2010)

Among the investigated isolates, the highest percentage of resistance $(82.6 \%)$ was detected against penicillin that could be attributed to the long-term use in agricultural and healthcare settings (Moon et al., 2007).

Resistance of $S$. aureus to penicillins is a well-known phenomenon worldwide but varies in its rate depending on the geographical location (Vintov et al., 2003).

The recorded percentage is higher than those identified by Rajala-Schultz et al. (2004) and Alian et al. (2012) while higher rates were noted by $\mathrm{Pu}$ et al. (2014) and Jamali et al. (2014).

Cefoxitin DD test was employed in this study for phenotypic characterization of MRSA. This test is able to foretell the presence of mecA gene in S. aureus with a high degree of sensitivity and specificity (Swenson et al., 2005 and CLSI, 2013).

Nearly $47.8 \%$ of the total isolates were considered as MRSA. Literatures showed that the prevalence of MRSA among $S$. aureus isolates was as high as 52\% between 2003 and 2005 in Egypt (Falagas et al., 2013).

Methicillin resistance in $S$. aureus is principally mediated by mecA gene, which located on a mobile genetic element and encodes an altered penicillinbinding protein (PBP2a) with an extremely low affinity to beta-lactam antibiotics (Hiramatsu et al., 2001). Regarding MRSA as a critically important human pathogen (Verkade and Kluytmans, 2014), detection of MRSA in milk of dairy cattle could represent a source of zoonotic transmission between livestock and humans (Harrison et al., 2013 and Petersen et al., 2013).

Egypt. J. Vet. Sci. Vol. 45-46 (2014 - 2015) 
Biofilm formation has an essential role in the virulence of $S$. aureus isolated from bovine intramammary infections (Vasudevan et al., 2003 and Fox et al., 2005). Literature recommended both phenotypic and genotypic methods for investigating biofilm forming ability in S. aureus (Vasudevan et al., 2003 and De Castro Melo et al., 2013).

All the tested isolates were seeded on CRA to evaluate their biofilm forming ability as a phenotypic method and 18 (78.3\%) of them were recorded as biofilm producers.

Nearer results were mentioned by Darwish and Asfour (2013) and De Castro Melo et al.(2013) while lower percentages were observed by Fox et al. (2005) and Krukowski et al. (2008).

On the other hand, the biofilm related genes, icaA and icaD were detected simultaneously in $91.3 \%$ of the total isolates. The percentage is comparable to that of Vasudevan et al. (2003) and De Castro Melo et al. (2013).

The total isolates were also investigated for the presence of bap gene that encoding the biofilm associated protein and it was detected in only one isolate (4.3\%).This very low prevalence was correlated to that reported by Cucarella et al. (2001) and Darwish and Asfour (2013). Other authors did not detect the bap gene in their S. aureus isolates of intramammary origin (Vautor et al., 2008, Melchior et al., 2009 and Szweda et al., 2012).

Detection of ica locus in some of the tested isolates although they failed to produce biofilm on CRA may be due to the high sensitivity of these isolates to the growth conditions as previously suggested by Cramton et al. (1999) or could be due to some capsular exopolysaccharides that required in the biofilm production are not well expressed in the presence of oxygen but they require $\mathrm{Co}_{2}$ (Gotz, 2002).

It can be concluded that, some of the investigated isolates showed multiple drug resistance to the most commonly used antibiotics, high percentage of them was categorized as MRSA with high capability for biofilm formation a fact representing a hazard to public health

Acknowledgment : I would like to express my special thanks to Prof. Dr. Ismail Abd El-Hafeez Radwan, Prof. and head of Bacteriology, Mycology and Immunology Department, Faculty of Veterinary Medicine, Beni-Suef University and Prof. Dr. Walid Hammdy Hassan, Prof. of Bacteriology, Mycology and Immunology, Beni-Suef University for their fruitful efforts and support throughout the work. 


\section{References}

Alian, F., Rahimi, E., Shakerian, A., Momtaz, H., Riahi, M. and Momeni, M. (2012) Antimicrobial resistance of Staphylococcus aureus isolated from bovine, sheep and goat raw milk, G.V., 8, 111-114.

Amin, A.S., Hamouda, R.H. and Abdel-All, A.A. (2011) PCR Assays for Detecting Major Pathogens of Mastitis in Milk Samples. W.J.D.F.S., 6 (2), 199-206.

Bergonier, D., Sobral, D., Feßler, A.T., Jacquet, E., Gilbert, F.B., Schwarz, S., Treilles, M., Bouloc, P., Pourcel, C. and Vergnaud, G. (2014) Staphylococcus aureus from 152 cases of bovine, ovine and caprine mastitis investigated by Multiplelocus variable number of tandem repeat analysis (MLVA). Vet. Res., 45, 97-102.

Ciftci, A., Findik, A., Onuk, A. and Savasan, S. (2009) Detection of methicillin resistance and slime factor production of Staphylococcus aureus in bovine mastitis. Braz. J. Microbiol., 40 (2), 254 - 261.

CLSI (2013) Performance standards for antimicrobial susceptibility testing; twenty-third informational supplement. M100-S23, Clinical and Laboratory Standards Institute; Wayne, PA, USA.

Collee, J.G., Fraser, A.G., Marmion, B.P. and Simmons, A. (1996) Bacteria and related organisms. In: Mackie and McCartney's Practical Medical Microbiology, $14^{\text {th }}$ ed. Churchill living stone, Edinburgh and New York, pp. 131-149.

Costerton, J.W., Stewart, P.S. and Greenberg, E.P. (1999) Bacterial biofilms: a common cause of persistent infections. Science., 284 (5418), 1318-1322.

Cramton, S.E., Gerke, C., Schnell, N.F., Nichols, W.W. and Götz, F. (1999) The intercellular adhesion (ica) locus is present in Staphylococcus aureus and is required for biofilm formation. Infect Immun., 67(10), 5427-5433.

Cucarella, C., Solano, C., Valle, J., Amorena, B., Lasa, I. and Penades, J.R. (2001) Bap, a Staphylococcus aureus surface protein involved in biofilm formation. $J$. Bacteriol., 183 (9), 2888-2896.

Cucarella, C., Tormo, M.A., Ubeda, C., Trotonda, M.P., Monzón, M., Peris, C., Amorena, B., Lasa, I. and Penadés, J.R. (2004) Role of biofilm-associated protein bap in the pathogenesis of bovine Staphylococcus aureus. Infect. Immun., 72(4), 2177-2185.

Darwish S.F. and Asfour, H.A. (2013) Investigation of biofilm forming ability in Staphylococci causing bovine mastitis using phenotypic and genotypic assays. Sci. World J., $378-492$.

De Castro Melo, P., Ferreira L. M., Filho A.N., Zafalon L.F., Vicente H.I. and De Souza V. (2013) Comparison of methods for the detection of biofilm formation by Staphylococcus aureus isolated from bovine subclinical mastitis. Braz J. Microbiol., 44 (1), 119-124.

Egypt. J. Vet. Sci. Vol. 45-46 (2014 - 2015) 
Falagas, M.E., Karageorgopoulos, D.E., Leptidis, J. and Korbila, I.P. (2013) MRSA in Africa: filling the global map of antimicrobial resistance. PLoS One. 8(7), e68024.

Fox, L.K., Zadoks, R.N. and Gaskins, C.T. (2005) Biofilm production by Staphylococcus aureus associated with intramammary infection. Vet. Microbiol., 107 (3-4), 295-299.

Freeman, D.J., Falkiner, F.R. and Keane, C.T. (1989) New method for detecting slime production by coagulase negative Staphylococci. J. Clin. Pathol., 42 (8), 872-874.

Gianneechini, R., Concha, C., Rivero, R., Delucci, I. and Moreno López, J. (2002) Occurrence of clinical and sub-clinical mastitis in dairy herds in the West Littoral Region in Uruguay. Acta Vet. Scand., 43 (4), 221-230.

Götz, F. (2002) Staphylococcus and biofilms. Mol. Microbiol., 43 (6), 1367-1378.

Harrison, E.M., Paterson, G.K., Holden, M.T., Larsen, J., Stegger, M., Larsen, A.R., Petersen, A., Skov, R.L., Christensen, J.M., Bak Zeuthen, A., Heltberg, O., Harris, S.R., Zadoks, R.N., Parkhill, J., Peacock, S.J. and Holmes, M.A. (2013) Whole genome sequencing identifies zoonotic transmission of MRSA isolates with the novel mecA homologue mecC. EMBO Mol. Med., 5 (4), 509-515.

Hiramatsu, K., Cui, L.Z., Kuroda, M. and Ito, T. (2001) The emergency and evolution of methicillin-resistant Staphylococcus aureus. TRENDS Microbiol., 9, 486-493.

Jamali, H., Radmehr, B., and Ismail, S. (2014) Prevalence and antibiotic resistance of Staphylococcus aureus isolated from bovine clinical mastitis. J. Dairy Sci., 97 (4), 2226-2230.

Krukowski, H., Szymankiewicz, M. and Lisowski, A. (2008) Slime production by Staphylococcus aureus strains isolated from cases of bovine mastitis. Pol. J. Microbiol., 57 (3), 253-255.

Kumar, R., Yadav, B.R. and Singh, R.S. (2010) Genetic Determinants of Antibiotic Resistance in Staphylococcus aureus Isolates from Milk of Mastitic Crossbred Cattle. Curr. Microbiol., 60 (5), 379-386.

Latasa, C., Solano, C., Penadés, J.R. and Lasa, I. (2006) Biofilm-associated proteins. C. R. Biol., 329 (11), 849-857.

Melchior, M.B., Vaarkamp, H. and Fink-Gremmels, J. (2006) Biofilms: A role in recurrent mastitis infections? Vet. J., 171 (3), 398-407. 
Melchior, M.B., van Osch, M.H., Graat, R.M., van Duijkeren, E., Mevius, D.J., Nielen, M., Gaastra, W. and Fink-Gremmels, J. (2009) Biofilm formation and genotyping of Staphylococcus aureus bovine mastitis isolates: evidence for lack of penicillin-resistance in Agr-type II strains. Vet. Microbiol., 137(1-2), 83-89.

Moon, J.S., Lee, A.R., Kang, H.M., Lee, E.S., Kim, M.N., Paik, Y.H., Park, Y.H., Joo, Y.S. and Koo, H.C. (2007) Phenotypic and genetic antibiogram of methicillinresistant staphylococci isolated from bovine mastitis in Korea. J. Dairy. Sci., 90 (3), 1176-1185.

Petersen, A., Stegger, M., Heltberg, O., Christensen, J., Zeuthen, A., Knudsen, L.K., Urth, T., Sorum, M., Schouls, L., Larsen, J., Skov, R. and Larsen, A.R. (2013) Epidemiology of methicillin resistant Staphylococcus aureus carrying the novel mecC gene in Denmark corroborates a zoonotic reservoir with transmission to humans. Clin. Microbiol. Infect., 19 (1), E16-22.

Pu, w., Su, Y., Li, J., Li, C., Yang, Z., Deng, H. and Ni, C. (2014) High incidence of oxacillin-susceptible mecA-positive Staphylococcus aureus (OS-MRSA) associated with bovine mastitis in China. Plos One., 9 (2), e88134.

Rajala-Schultz, P.J., Smith, K.L., Hogan, J.S. and Love, B.C. (2004) Antimicrobial susceptibility of mastitis pathogens from first lactation and older cows, Vet. Microbiol., 102(1-2), 33-42.

Schalm, O.W. and Noorlander, D.O. (1957) Experiments and observations leading to development of the California mastitis test. J. Am. Vet. Med. Assoc., 130, 199-204.

Shi, D., Hao, Y., Zhang, A., Wulan, B. and Fan, X. (2010) Antimicrobial Resistance of Staphylococcus aureus Isolated From Bovine Mastitis in China. Transbound Emerg Dis., 57(4), 221-224.

Swenson, J.M., Tenover, F.C. and Cefoxitin Disk Study Group (2005) Results of disk diffusion testing with cefoxitin correlate with presence of mecA in Staphylococcus spp. J. Clin. Microbiol., 43 (8), 3818-3823.

Thompson-Crispi, K., Atalla, H., Miglior, F. and Mallard, B.A. (2014) Bovine mastitis:frontiers in immunogenetics. Front. Immunol., 5, 493-495.

Vancraeynest, D., Hermans, K. and Haesenbrouck, F. (2004) Gentotypic and phenotypic screening of high and low virulence Staphylococcus aureus isolates from rabbits for biofilm formation and MSCRAMMs. Vet. Microbiol., 103(3-4), 241-247.

Vasudevan, P., Nair, M.K., Annamalai, T. and Venkitanarayanan, K.S. (2003) Phenotypic and genotypic characterization of bovine mastitis isolates of Staphylococcus aureus for biofilm formation.Vet. Microbiol., 92 (1-2), 179-185.

Egypt. J. Vet. Sci. Vol. 45-46 (2014 - 2015) 
Vautor, E., Abadie, G., Pont, A. and Thiery, R.E. (2008) Evaluation of the presence of the bap gene in Staphylococcus aureus isolates recovered from human and animals species. Vet. Microbiol., 127 (3 - 4), 407-411.

Verkade, E. and Kluytmans, J. (2014) Livestock-associated Staphylococcus aureus CC398: animal reservoirs and human infections. Infect. Genet. Evol., 21, 523-530.

Vintov, J., Aarestrup, F.M., Zinn, C.E. and Olsen, J.E. (2003) Association between phage types and antimicrobial resistance among bovine Staphylococcus aureus from 10 countries. Vet. Microbiol., 95(1-2), 133-147.

Szweda, P., Schielmann, M. Milewski, S. Frankowska, A. and Jakubczak, A. (2012) Biofilm production and presence of ica and bap genes in Staphylococcus aureus strains isolated from cows with mastitis in the eastern Poland. Pol. J. Microbiol., 61(1), 65-69.

(Received 29/7/2015;

accepted 29/10/2015) 


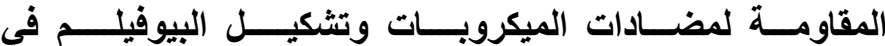
الستافيلوكوكس اوريس المعزولة من التهاب الضروع في الأبقار في في

قسم البكتريا والفطريات والمن والمناعة ـ كلية الطب البيطرى - جامعة بنى سويف ـ

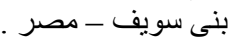

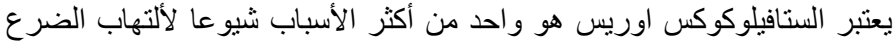

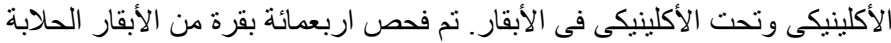

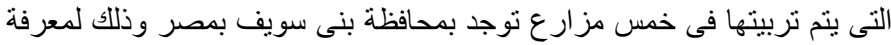

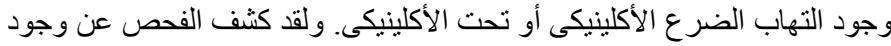

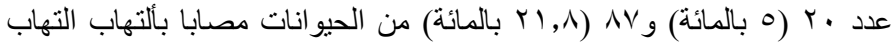

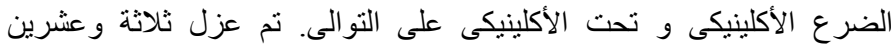

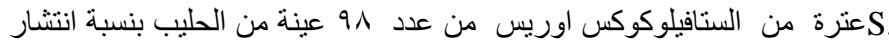

$\%$ \% , O

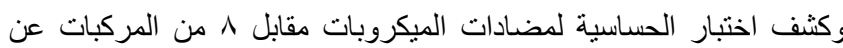

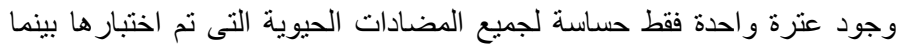

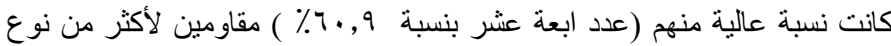

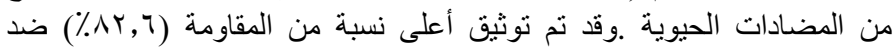

البنسلين.

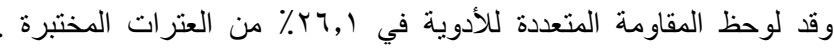

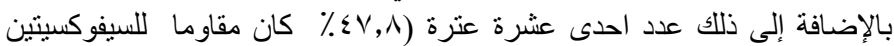

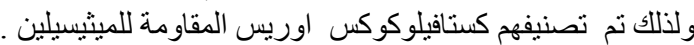

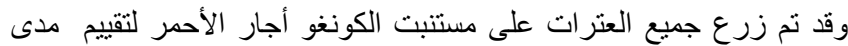

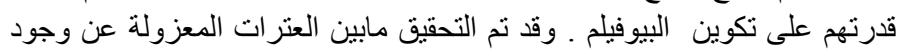
جينات icaA, icaD, bap وقد اسفر ذلك عن وجود جينى

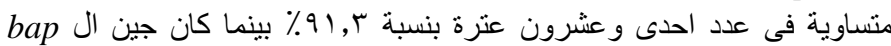

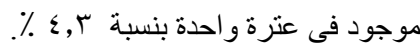

